\title{
Decay times of 4-(dimethylamino)benzonitrile in acetonitrile and conclusions on entropy of activation
}

\author{
Klaas A. Zachariasse ${ }^{\mathrm{a}, *}$, Sergey I. Druzhinin ${ }^{\mathrm{a}, *}$, Peter Mayer $^{\mathrm{b}}$, Sergey A. Kovalenko ${ }^{\mathrm{c}, *}$, Tamara Senyushkina ${ }^{\mathrm{a}}$ \\ a Max-Planck-Institut für biophysikalische Chemie, Spektroskopie und Photochemische Kinetik, 37070 Göttingen, Germany \\ ${ }^{\mathrm{b}}$ Department Chemie und Biochemie, Ludwig-Maximilians-Universität, Butenandtstrasse 5-13, Haus F, 81377 München, Germany \\ ${ }^{\mathrm{c} I n s t i t u t ~ f u ̈ r}$ Chemie, Humboldt Universität zu Berlin, Brook-Taylor Strasse 2, 12489 Berlin, Germany
}

\section{A R T I C L E I N F O}

Article history:

Received 13 October 2009

In final form 30 October 2009

Available online 5 November 2009

\begin{abstract}
A B S T R A C T
From picosecond decay times of 4-(dimethylamino)benzonitrile (DMABN) and 4-(dimethylamino)benzoic acid ethyl ester (DMABE) in acetonitrile (Ref. [1]), a conclusion on entropy effects cannot be made because of large uncertainties of the data. The planarized 1-tert-butyl-6-cyano-1,2,3,4-tetrahydroquinoline (NTC6) as a model for a planar intramolecular charge transfer (ICT) state and the influence of pretwist and size of the amino group is also discussed. For DMABE excited state absorption spectra show a decay of the locally excited (LE) and a rise of the ICT state of $1.0 \mathrm{ps}$, posing the question whether the lowest excited singlet state is of $\mathrm{L}_{\mathrm{b}}$ or $\mathrm{L}_{\mathrm{a}}$ character.
\end{abstract}

(ㄷ) 2009 Elsevier B.V. All rights reserved.

\section{Introduction}

In a recent Letter [1], Rettig and coworkers presented decay times of five electron donor (D)/acceptor (A) molecules in acetonitrile $(\mathrm{MeCN})$ undergoing a reaction from the locally excited (LE) state to the intramolecular charge transfer (ICT) state. These decay times were determined at $20^{\circ} \mathrm{C}$ by fluorescence upconversion, at a wavelength $(350 \mathrm{~nm})$ where only LE fluorescence occurs and also at a second wavelength $(500 \mathrm{~nm})$ at which predominantly ICT emission is detected [2]. For two of the D/A molecules, the decay time $\tau$ was measured at more than one temperature: at $-15,20$ and $36^{\circ} \mathrm{C}$ for 4 -(dimethylamino)benzonitrile (DMABN) and at $-15,-7,22$ and $38^{\circ} \mathrm{C}$ for 4 -(dimethylamino)benzoic acid ethyl ester (DMABE). This was done at an intermediate wavelength $(430 \mathrm{~nm})$, where more LE emission is present under the major broad ICT fluorescence band than at $500 \mathrm{~nm}$ [2]. The quality of fit for the upconversion traces cannot be ascertained, as residuals are not shown. From these data, Arrhenius activation energies, preexponential factors and entropy effects were obtained. These results are critically discussed in the present Letter. The significance of the planarized A/D molecule 1-tert-butyl-6-cyano1,2,3,4-tetrahydroquinoline (NTC6) in connection with the molecular structure of the ICT state of DMABN as well as the ICT reaction and precursor of DMABE will also be treated.

\section{Experimental}

The synthesis and purification of aldehyde-free DMABN was described before [2]. DMABE (Aldrich) was recrystallized from light

\footnotetext{
* Corresponding authors. Fax: +49 5512011501 (K.A. Zachariasse).

E-mail address: kzachar@gwdg.de (K.A. Zachariasse).
}

petroleum. The solvents were chromatographed over $\mathrm{Al}_{2} \mathrm{O}_{3}$. The details of the time-correlated single photon counting (SPC) and transient absorption measurements were reported previously [2].

\section{Results and discussion}

\subsection{Picosecond decay times of DMABN in $\mathrm{MeCN}$}

For the three temperatures at which the fluorescence decay time $\tau$ is determined for DMABN in MeCN, an Arrhenius plot is presented in Fig. 1 (red points): $1 / \tau_{2} \sim k_{\mathrm{a}}^{0} \exp \left(-E_{\mathrm{a}} / R T\right)$. These data show a substantial scatter, as reflected in the exceptionally large uncertainty reported for the activation energy $E_{\mathrm{a}}$ of the LE $\rightarrow$ ICT reaction rate constant $k_{\mathrm{a}}$ (Scheme 1): $1.4 \pm 1.9 \mathrm{~kJ} / \mathrm{mol}$ [1]. An equally large scatter was found for DMABE: $2.0 \pm 2.3 \mathrm{~kJ} / \mathrm{mol}[1]$.

In looking at these results, it should be noted that only the shortest decay time $\tau_{2}$ of the double exponential LE and ICT fluorescence decays (Eqs. (1)-(4)) is taken into account in Ref. [1]. Although fluorescence decays generally are double exponential when two kinetically communicating excited states (LE and ICT) are involved (Scheme 1), this approximation is acceptable for DMABN in $\mathrm{MeCN}$ at $25^{\circ} \mathrm{C}$. This can be seen from the following data that have been reported for this system [2]: $\tau_{2}=4.1 \mathrm{ps}$ and $\tau_{1}=3800 \mathrm{ps}$, with an amplitude ratio $A=A_{12} / A_{11}$ of 393 (516 after correction for photoproducts), see Eqs. (1)-(4)

$$
\begin{aligned}
& i_{f}(\mathrm{LE})=A_{11} \exp \left(-t / \tau_{1}\right)+A_{12} \exp \left(-t / \tau_{2}\right) \\
& i_{f}(\mathrm{ICT})=A_{21} \exp \left(-t / \tau_{1}\right)+A_{22} \exp \left(-t / \tau_{2}\right) \\
& A=A_{12} / A_{11} \\
& A_{21}=-A_{22}
\end{aligned}
$$




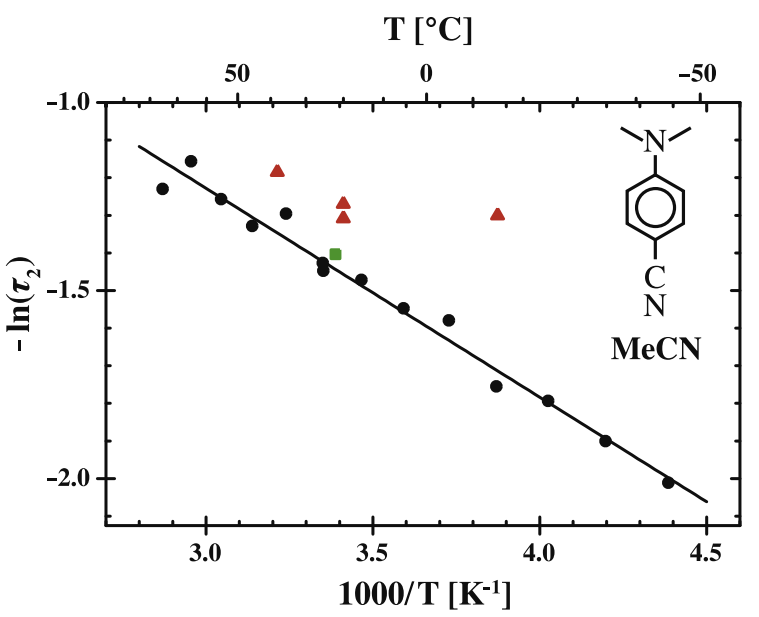

Fig. 1. Plot of $-\ln \left(\tau_{2}\right)$ ( $\tau_{2}$ in ps) for $D M A B N$ in acetonitrile (MeCN) vs. the reciprocal absolute temperature. Data points: red (upconversion, Ref. [1]); green (femtosecond excited state absorption, Ref. [2]); black (picosecond single photon counting, Ref. [2]). (For interpretation of the references to colour in this figure legend, the reader is referred to the web version of this article.)

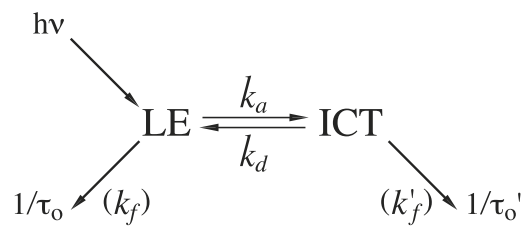

Scheme 1.

In the approach of Ref. [1], one then obtains the following approximate, but for DMABN/MeCN adequate, expressions

$$
\begin{aligned}
& i_{f}(\mathrm{LE})=A_{11}+A_{12} \exp \left(-t / \tau_{2}\right) \\
& i_{f}(\mathrm{ICT})=A_{21}+A_{22} \exp \left(-t / \tau_{2}\right)
\end{aligned}
$$

For the normalized LE decay (Eq. (5)), $A_{11}+A_{12}=1$, equivalent to $A_{0}+A_{1}=1$ in Table 1 of Ref. [1]. This expression does not hold, however, in the case of the ICT decay at $500 \mathrm{~nm}$ in this table, as then (Eq. (6)) $A_{0}+A_{1}=0$, see Eq. (4). It also does not hold strictly for the decay at $430 \mathrm{~nm}$ (sum of ICT and LE fluorescence, Eqs. (5) and (6)), see Fig. 2.

In Scheme $1, k_{\mathrm{a}}$ and $k_{\mathrm{d}}$ are the rate constants of the forward and backward ICT reaction, $\tau_{0}$ (LE) and $\tau_{0}^{\prime}$ (ICT) are the fluorescence lifetimes, whereas $k_{\mathrm{f}}(\mathrm{LE})$ and $k_{\mathrm{f}}^{\prime}(\mathrm{ICT})$ are the radiative rate constants.

Decay times $\tau_{2}$ for DMABN in MeCN published in Ref. [2] are also plotted in Fig. 1. From the global analysis of 14 fluorescence decays obtained from picosecond single photon counting (SPC) experiments (black data points) together with the fluorescence spectra, over a temperature range from 75 to $-45{ }^{\circ} \mathrm{C}$, an activation

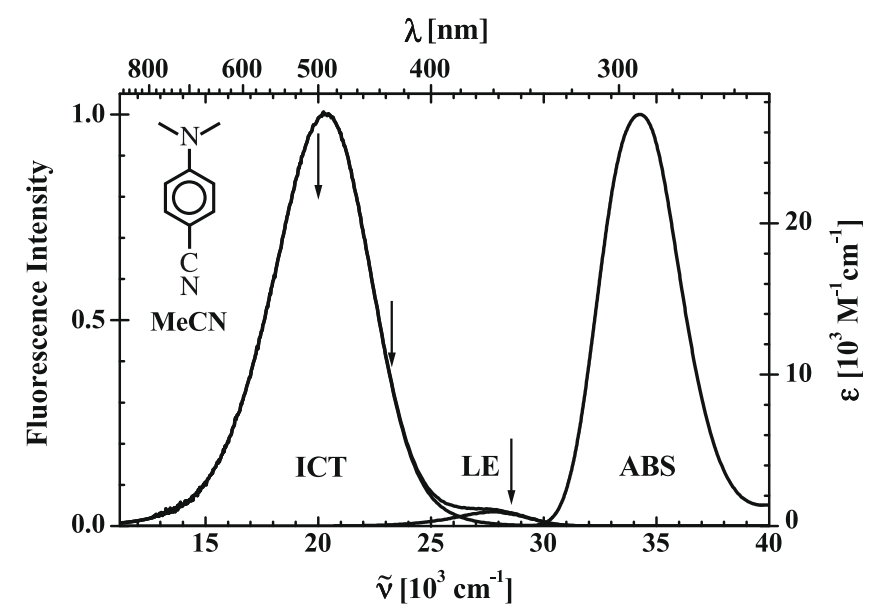

Fig. 2. Fluorescence and absorption spectra of 4-(dimethylamino)benzonitrile (DMABN) in acetonitrile $(\mathrm{MeCN})$ at $25^{\circ} \mathrm{C}$. The molar extinction coefficient is indicated on the right hand axis. The fluorescence spectrum of DMABN in MeCN is separated into its locally excited (LE) and intramolecular charge transfer (ICT) components, by using the LE fluorescence spectrum of 4-(methylamino)benzonitrile (MABN). The arrows indicate the emission wavelengths 500, 430 and $350 \mathrm{~nm}$.

energy $E_{\mathrm{a}}$ of $5.0 \pm 0.25 \mathrm{~kJ} / \mathrm{mol}$ and a preexponential factor $k_{\mathrm{a}}^{0}=1.83 \times 10^{12} \mathrm{~s}^{-1}$ have been calculated (Ref. [2]). From Fig. 1 (including the green ESA data point): $E_{\mathrm{a}}=4.6 \pm 0.2 \mathrm{~kJ} / \mathrm{mol}$ and $k_{\mathrm{a}}^{0}=1.6 \pm 0.1 \times 10^{12} \mathrm{~s}^{-1}$. The value for $E_{\mathrm{a}}$ is clearly considerably larger and less uncertain than that $(1.4 \pm 1.9 \mathrm{~kJ} / \mathrm{mol})$ of Ref. [1]. The authors of Ref. [1] claim that this large difference in the $\tau_{2}$ values is caused by the fact that their data are more reliable in view of an presumed better time resolution of their equipment. They report for our SPC equipment a 19 ps apparatus response function, implying that this is too large for an accurate determination of the decay times of DMABN in $\mathrm{MeCN}$, between 7.8 and $3.0 \mathrm{ps}$, our data from Ref. [2]. In fact, the time resolution in our SPC experiments is after deconvolution better than 3 ps [2], which means that our decay times in Ref. [2] are not affected by insufficient time resolution. This conclusion is fully supported by the $\tau$ of $4.07 \mathrm{ps}$ (green data point in Fig. 2) determined from femtosecond excited state absorption (ESA) measurements of DMABN in MeCN at $22{ }^{\circ} \mathrm{C}$, having a time resolution better than $100 \mathrm{fs}$ [2]. We therefore conclude that the scatter in the decay times of Ref. [1] and also their small number and narrow temperature range prevent a meaningful determination of the activation energy of the LE $\rightarrow$ ICT reaction of DMABN in MeCN. This also means that reliable information on the preexponential factor $k_{\mathrm{a}}^{0}$ of this reaction and $a$ fortiori on its entropy of activation $\Delta S^{\neq}$cannot be obtained from the data presented in Ref. [1], neither for DMABN nor for DMABE.

Within the context of transition state theory (TST) [3], the rate constant $1 / \tau_{2}=k_{\mathrm{a}}$ for the LE $\rightarrow$ ICT reaction can be written in terms of the entropy and enthalpy of activation $\Delta S^{\neq}$and $H^{\neq}$, Eq. (7). A

Table 1

\begin{tabular}{|c|c|c|c|c|c|c|c|}
\hline & $\begin{array}{l}T \\
\left({ }^{\circ} \mathrm{C}\right)\end{array}$ & $\begin{array}{l}\tau_{2} \\
(\mathrm{ps})\end{array}$ & $\begin{array}{l}k_{\mathrm{a}}{ }^{\mathrm{a}} \\
\left(10^{11} \mathrm{~s}^{-1}\right)\end{array}$ & $\begin{array}{l}E_{\mathrm{a}} \\
(\mathrm{kJ} / \mathrm{mol})\end{array}$ & $\begin{array}{l}k_{a}^{0} \\
\left(10^{12} \mathrm{~s}^{-1}\right)\end{array}$ & $\begin{array}{l}\Delta H^{\neq} \\
(\mathrm{kJ} / \mathrm{mol})\end{array}$ & $\begin{array}{l}\Delta S^{f} \\
\left(\mathrm{JK}^{-1} \mathrm{~mol}^{-1}\right)\end{array}$ \\
\hline DMABN (Ref. [1]) & 20 & 3.7 & 2.7 & $1.4 \pm 1.9$ & $0.49 \pm 0.15$ & $-1.2 \pm 0.8$ & $-30 \pm 3$ \\
\hline DMABE (Ref. [1]) & 20 & 0.92 & 10.9 & $2.0 \pm 2.3$ & $2.4 \pm 0.3$ & $-0.15 \pm 0.44$ & $-15.2 \pm 1.5$ \\
\hline DMABN (Ref. [2]) & 25 & 4.10 & 2.4 & $5.0 \pm 0.25$ & $1.83 \pm 0.02$ & $2.3 \pm 0.2$ & $-19.4 \pm 0.7$ \\
\hline DMABN (Ref. [2]) & 20 & 4.28 & 2.3 & $5.0 \pm 0.25$ & $1.83 \pm 0.02$ & $2.3 \pm 0.2$ & $-19.4 \pm 0.7$ \\
\hline DMABN (Ref. [2]) & -45 & 7.35 & 1.3 & $5.0 \pm 0.25$ & $1.83 \pm 0.02$ & $2.3 \pm 0.2$ & $-19.4 \pm 0.7$ \\
\hline DMABN (Ref. [2]) & & & & $4.6 \pm 0.19$ & $1.56 \pm 0.13$ & $2.3 \pm 0.2$ & $-19.3 \pm 0.7$ \\
\hline
\end{tabular}

Data for DMABN and DMABE in MeCN.

${ }^{\text {a }} k_{\mathrm{a}}=1 / \tau_{2}$ (Scheme 1$)$.

$\mathrm{b}$ Effective parameters from the plots of our combined SPC and ESA data in Figs. 1 and 3. 
plot of $\ln \left(h / k T \tau_{2}\right)$ vs. $1000 / T$ is presented in Fig. 3. It appears that now the upconversion data (red points) result in a positive slope, meaning that the enthalpy of activation is negative: $-1.2 \pm 0.8 \mathrm{~kJ} /$ mol and $\Delta S^{f}=-30 \pm 3 \mathrm{JK}^{-1} \mathrm{~mol}^{-1}$. For our SPC and ESA data, the value for $\Delta H^{\neq}$is positive $(2.3 \pm 0.2 \mathrm{~kJ} / \mathrm{mol}$ and $\left.\Delta S^{f}=-19.7 \pm 0.7 \mathrm{JK}^{-1} \mathrm{~mol}^{-1}\right)$, but smaller than that for $E_{\mathrm{a}}$ $(4.6 \pm 0.2 \mathrm{~kJ} / \mathrm{mol})$, a natural consequence of the temperature dependence of the preexponential factor in the TST treatment (Table 1).

$1 / \tau_{2} \sim k_{\mathrm{a}}=k T / h \exp \left(\Delta S^{\neq} / R\right) \exp \left(-\Delta H^{\neq} / R T\right)$

\subsection{NTC6, a planar ICT model compound for DMABN}

NTC6 (Chart 1) undergoes a fast ICT reaction, with a reaction time (decay time $\tau_{2}$ ) of $2.1 \mathrm{ps}$ in $n$-hexane at $25^{\circ} \mathrm{C}$ and $1.0 \mathrm{ps}$ in $\mathrm{MeCN}$ at $22^{\circ} \mathrm{C}[4,5]$. The activation energy $E_{\mathrm{a}}$ is very low, $1 \mathrm{~kJ} / \mathrm{mol}$ in di(n-butyl) ether [4]. In the ICT state of NTC6 obtained from calculations, the conjugation in the phenyl ring is destroyed, brought about by the pyramidal configuration of the atom $\mathrm{C} 4$ to which the amino nitrogen N7 is attached [6,7]. A similarly distorted pyramidal ICT structure has been calculated for DMABN $[8,9]$. For such a substantial structural distortion, a small activation barrier as revealed by the fast ICT reaction of NTC6 would be surprising. In the calculations on NTC6, an activation energy for the LE $\rightarrow$ ICT reaction pathway has not been reported [6,7].

It is then to be expected that the ICT ESA spectrum of NTC6 with a distorted phenyl ring would be different from that of the benzonitrile radical anion, in which all $C$ atoms of the phenyl ring are conjugated, as deduced from its ESR spectrum [10]. This is not the case, however, as the transient spectrum of the ICT state of NTC6 resembles that of the benzonitrile anion [5], similar to what

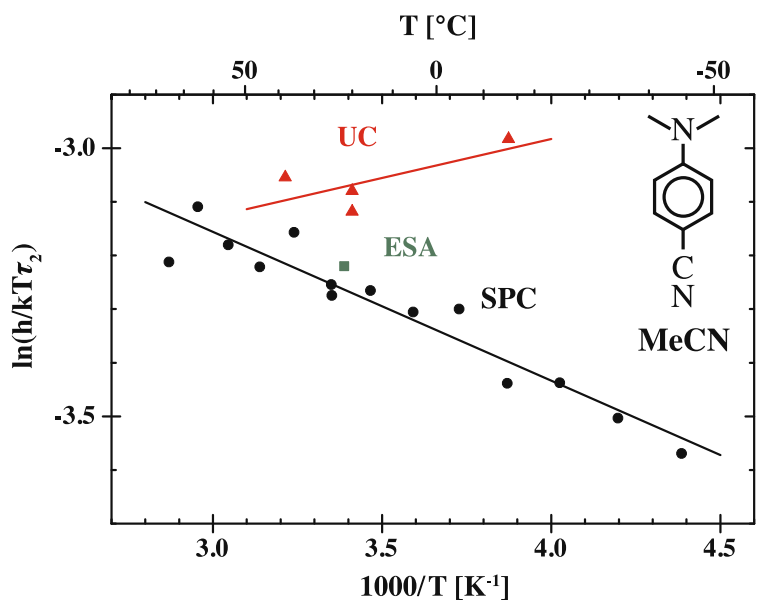

Fig. 3. Plot of $\ln \left(h / k T \tau_{2}\right)$ for DMABN in acetonitrile (MeCN) vs. the reciprocal absolute temperature. Data points: red (upconversion, Ref. [1]); green (femtosecond excited state absorption, Ref. [2]); black (picosecond single photon counting, Ref. [2]). (For interpretation of the references to colour in this figure legend, the reader is referred to the web version of this article.)
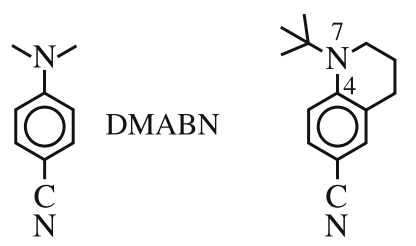

NTC6

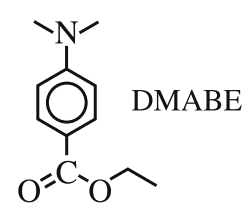

Chart 1. has been observed in the case of DMABN [2,11-13]. It should be noted in this connection that benzonitrile and derivatives with various para-substituents have similar radical anion absorption spectra $[14,15]$, indicating that structural information such as on the dimethylamino twist angle $\theta$ cannot be deduced from the ESA spectra. When a possibility to reach a strongly twisted ICT structure by phenyl ring distortion would exist for NTC6, it likewise would be expected for its $N$-methyl (NMC6), $N$-ethyl (NEC6) and $\mathrm{N}$-isopropyl (NIC6) derivatives, for which molecules, in fact, an ICT reaction does not occur [4].

\subsection{Amino twist angles in the $S_{0}$ ground state (pretwist)}

According to Ref. [1], deduced from photoelectron spectra [16], the dimethylamino group of DMABN is twisted over an angle $\theta$ of about $30^{\circ}$ relative to the plane of the benzonitrile moiety, whereas 4-(N-pyrrolino)benzonitrile (P5C, Chart 2 ) is close to planar. This is surprising, as in Ref. [16] a twist angle of around $0^{\circ}$ is reported for both molecules (Table 2). Also from an X-ray structure analysis of DMABN $[17,18]$ and P5C a small twist angle $\theta$ close to $0^{\circ}$ is found (Table 2).

The decadic molar absorption coefficients $\varepsilon^{\max }$ of the lowest-energy band in the absorption spectrum of DMABN and P5C in $n$-hexane and $\mathrm{MeCN}$ (Table 2) likewise lead to the conclusion that their amino group is not twisted. This comes from the condition that $\varepsilon^{\max }$ is proportional to $\cos ^{2} \theta$ [19]. A planar structure for DMABN in the ground state is also found by several computations $[6,9,20]$. The discussion in Ref. [1] of the difference in ICT reaction time between the effectively planar molecules DMABN and P5C based on assumed differences in their twist angle $\theta$ is therefore not relevant.

Data from X-ray crystal analysis (cif. files in Supplementary material) for 4-(diethylamino)benzonitrile (DEABN), 4-( $\mathrm{N}$-piperidino)benzonitrile (P6C) and 3,5-dimethyl-4-(diethylamino)benzonitrile (MMD) are also included in Table 2, together with $\varepsilon^{\max }$ values, for comparison with the $\theta$ (PE) results from photoelectron spectra, also serving as a further illustration of the relationship between the twist angle $\theta$ and $\varepsilon^{\max }$. Care must be taken in defining the amino twist angle $\theta$ and the pyramidal angle $\varphi$ for molecules with pyramidal amino groups, see footnotes $\mathrm{a}$ and $\mathrm{b}$ of Table 2 and Chart 2. Note that for P6C and MMD (Table 2) the angles $\theta$ and $\varphi$ both contribute to the electronic decoupling of the amino group from the benzonitrile moiety in aminobenzonitriles, an increase of both angles leading to a decrease of $\varepsilon^{\text {max }}$.

The influence of a 'pretwist' of the amino group of 4-aminobenzonitriles in the $S_{0}$ ground state on the efficiency of the $\mathrm{LE} \rightarrow \mathrm{ICT}$ reaction is questionable anyway, as the molecular structure of the $S_{1}(\mathrm{LE})$ state (twist angle, amino pyramidality, bond lengths) and not that of the ground state $S_{0}$ is significant for the ICT reaction. In addition, twist angles up to around $30^{\circ}$ will be of little photophysical consequence as compared to a planar structure, because of the fact that the electronic coupling between the amino and benzonitrile moieties is governed by $\cos ^{2} \theta[19]$.

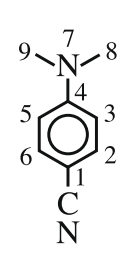

DMABN
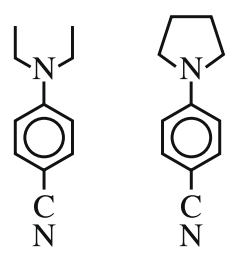

DEABN

P5C

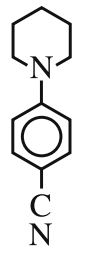<smiles>Cc1cc(C#N)cc(C)c1N(C)C</smiles>

P6C

MMD 
Table 2

Extinction coefficients and structural data for the 4-aminobenzonitriles DMABN, DEABN, P5C, P6C, and MMD in $n$-hexane and MeCN.

\begin{tabular}{|c|c|c|c|c|c|c|c|c|}
\hline & Solvent for $\varepsilon^{\max }$ & $\begin{array}{l}\varepsilon^{\max }\left(\lambda^{\max }\right) \\
\left(\mathrm{M}^{-1} \mathrm{~cm}^{-1}\right)(\mathrm{nm})\end{array}$ & $\begin{array}{l}\theta \text { (cryst. }^{\mathrm{a}} \\
\left({ }^{\circ}\right)\end{array}$ & $\begin{array}{l}\varphi \text { (cryst. }^{\mathrm{b}} \\
\left({ }^{\mathrm{o}}\right)\end{array}$ & $\begin{array}{l}\sum \mathrm{N}^{\mathrm{c}} \\
\left({ }^{\circ}\right)\end{array}$ & $\begin{array}{l}\mathrm{N}-\mathrm{C}^{\mathrm{d}} \\
(\mathrm{pm})\end{array}$ & $\begin{array}{l}\theta\left(\varepsilon^{\max }\right)^{\mathrm{e}} \\
\left({ }^{\mathrm{o}}\right)\end{array}$ & $\begin{array}{l}\theta(\mathrm{PE})^{\mathrm{f}} \\
\left({ }^{\mathrm{o}}\right)\end{array}$ \\
\hline DMABN & $\begin{array}{l}n \text {-Hexane } \\
\text { MeCN }\end{array}$ & $\begin{array}{l}29370(280.7) \\
27755(292.1)\end{array}$ & $\begin{array}{l}2.2^{\mathrm{g}} \\
(253 \mathrm{~K})\end{array}$ & $8.6^{\mathrm{g}}$ & $358.5^{g}$ & $136.5^{\mathrm{g}}$ & & $\begin{array}{l}4 \\
(0-28)\end{array}$ \\
\hline $\mathrm{DEABN}^{\mathrm{h}, \mathrm{i}}$ & $\begin{array}{l}n \text {-Hexane } \\
\text { MeCN }\end{array}$ & $\begin{array}{l}31795(292.1) \\
30480(279.4)\end{array}$ & $\begin{array}{l}6.0(\mathrm{~A}) \\
4.1(\mathrm{~B}) \\
(200 \mathrm{~K})\end{array}$ & $\begin{array}{l}1.3(\mathrm{~A}) \\
4.1(\mathrm{~B})\end{array}$ & $\begin{array}{l}359.0(\mathrm{~A}) \\
359.8(\mathrm{~B})\end{array}$ & 136.0 & & $\begin{array}{l}21 \\
(11-28)\end{array}$ \\
\hline $\mathrm{P} 5 \mathrm{C}^{\mathrm{i}}$ & $\begin{array}{l}n \text {-Hexane } \\
\text { MeCN }\end{array}$ & $\begin{array}{l}33220(283.9) \\
32190(296.0)\end{array}$ & $\begin{array}{l}4.4 \\
(200 \mathrm{~K})\end{array}$ & 9.1 & 359.0 & 136.6 & & $\begin{array}{l}0 \\
(0-17)\end{array}$ \\
\hline $\mathrm{P} 6 \mathrm{C}^{\mathrm{i}}$ & $\begin{array}{l}n \text {-Hexane } \\
\text { MeCN }\end{array}$ & $\begin{array}{l}25560(285.7) \\
24280(297.0)\end{array}$ & $\begin{array}{l}6.5 \\
(200 \mathrm{~K})\end{array}$ & 26.3 & 352.7 & 138.6 & $\begin{array}{l}26^{\mathrm{j}} \\
27^{\mathrm{j}}\end{array}$ & $\begin{array}{l}33 \\
(27-39)\end{array}$ \\
\hline MMD & $\begin{array}{l}n \text {-Hexane } \\
\text { MeCN }\end{array}$ & $\begin{array}{l}5100(302.6) \\
5700(314.0)\end{array}$ & $\begin{array}{l}57.4^{\mathrm{g}} \\
(173 \mathrm{~K})\end{array}$ & $24.4^{\mathrm{g}}$ & $353.8^{g}$ & $141.4^{\mathrm{g}}$ & $\begin{array}{l}65^{\mathrm{k}} \\
63^{\mathrm{k}}\end{array}$ & \\
\hline
\end{tabular}

a The twist angle $\theta$ is defined as $(C(3)-C(4)-N(7)-C(8)+C(3)-C(4)-N(7)-C(9)) / 2$, see the atom numbering in Chart 2 .

b The pyramidal angle $\varphi$ is defined as the angle between the vector $N(7)-C(4)$ and the plane $C(8)-N(7)-C(9)$, see the atom numbering in $C$ art 2 .

c $\Sigma \mathrm{N}$ is the sum of the angles around the amino $\mathrm{N}$ atom.

d Phenyl-amino bond distance $\mathrm{C}(4)-\mathrm{N}(7)$.

e Calculated employing $\varepsilon^{\max } \sim \cos ^{2} \theta$ (Ref. [19]).

${ }^{f}$ Ref. [16], from photoelectron (PE) spectra.

g Determined from the data in Ref. [17]. From the data in Ref. [18], the following values can be obtained for $\theta, \varphi$, and $\Sigma N$ in crystalline DMABN at three temperatures: 0.30 , $10.59,358.80$ (295 K), 2.18, 8.61, 359.23 (173 K), 0.28, 9.16, 359.09 (301 K).

$\mathrm{h}$ Two independent molecules $\mathrm{A}$ and $\mathrm{B}$ in the asymmetric unit.

i The cif. files of the X-ray crystal analysis for P5C, P6C and DEABN are presented in the (Supplementary material).

j Employing $\varepsilon^{\max }$ of DEABN as the reference compound with zero twist angle.

${ }^{\mathrm{k}}$ Employing $\varepsilon^{\max }$ of DMABN as the reference compound with zero twist angle.

\subsection{Size of amino substituents and ICT reaction rate}

In Ref. [1] it is stated that the larger rotational volume of the pyrrolidino group of P5C as compared with that of the dimethylamino group in DMABN contributes to a slower ICT reaction (longer decay time $\tau_{2}$ ) of the former molecule. To single out the influence of macroscopic solvent viscosity on the ICT reaction of a D/A molecule such as DMABN is a complicated issue due to the difficulty to change the viscosity by employing a series of solvents, without simultaneously changing other solvent properties such as polarity (dielectric constant $\varepsilon$ ) and polarizability (refractive index $n$ ). This is caused by the sensitivity of the ICT reaction on the magnitude of the energy gap $\Delta E\left(\mathrm{~S}_{1}, \mathrm{~S}_{2}\right)$, which gap is affected by $\varepsilon$ and $n$ [21-23]. This is even the case when the variation in viscosity is brought about by way of exerting hydrostatic pressure. In such a case measurements as a function of pressure have to be combined with those carried out at different temperatures. From such a combined experimental approach with DMABN in diethyl ether (DEE) at $20^{\circ} \mathrm{C}$ it was found that by increasing the pressure from 1 to $4500 \mathrm{bar}$, as an example, the solvent viscosity increased from 0.23 to $1.8 \mathrm{CP}$, whereas the polarity increased from 4.3 to 6.3 . By this increase in pressure, the ICT/LE fluorescence quantum yield ratio $\Phi^{\prime}(\mathrm{ICT}) / \Phi(\mathrm{LE})$ became larger, from 0.32 to 0.95 , making clear that the effect of pressure on solvent viscosity has a smaller impact on the ICT kinetics than that on polarity $[23,24]$.

For the relative small ICT reaction efficiency of P5C in MeCN the following different explanation can be found in the literature. The increase of the ICT rate constant $k_{\mathrm{a}}$ with increasing size of the cyclic amino group in the series 4 -( $N$-azetidino)benzonitrile (P4C), P5C, $\mathrm{P} 6 \mathrm{C}$ in $\mathrm{MeCN}$, although the volume of the cyclic amino group becomes larger, has been attributed to the lowering of the amino nitrogen inversion barrier for the LE $\rightarrow$ ICT reaction when going from P4C to P6C [25].

\subsection{ESA spectra of DMABE in MeCN. $S_{1}\left(L_{b}\right)$ and $S_{2}\left(L_{a}\right)$ states}

It is reported in Ref. [1] that the LE and ICT fluorescence bands of DMABE are both long-axis polarized. From this information, the question whether the lowest excited singlet state $S_{1}(L E)$ is of ${ }^{1} L_{b}$ or
${ }^{1} \mathrm{~L}_{\mathrm{a}}$ nature can, however, not easily be decided with certainty, as the $S_{1}$ and $S_{2}$ states in the absorption spectrum are in close proximity. Experimentally, it is very difficult to interpret the polarization direction when $S_{1}\left({ }^{1} L_{b}\right)$ is just below $S_{2}\left({ }^{1} L_{a}\right)$, due to vibronic coupling between these states, apart from the intrinsic difficulty to measure the $S_{1}$ absorption band separately under these conditions. Ironically, perhaps, the TICT model was introduced because of the finding that LE and ICT fluorescence of DMABN in glycerine both had a long-axis polarization $[11,26]$, thereby not taking the vibronic coupling between these close-lying states into account.

From ESA spectra of DMABE in $\mathrm{MeCN}$ at $22^{\circ} \mathrm{C}$ (Fig. 4a) it appears that the band with a maximum at $375 \mathrm{~nm}$ decays with 1.0 ps (Fig. 4b) [27], a time similar to the fluorescence decay of 0.98 ps reported in Ref. [1]. The band integral around the ICT absorption maximum at $465 \mathrm{~nm}$ shows a growing-in with the same time of $1.0 \mathrm{ps}$. This means that the $375 \mathrm{~nm}$ ESA band can be attributed to the initially excited $S_{1}(\mathrm{LE})$ state, the precursor in the ICT reaction. Whether this LE state is of $\mathrm{L}_{\mathrm{b}}$ or $\mathrm{L}_{\mathrm{a}}$ parentage cannot easily be decided. For DMABN in $n$-hexane, the energy gap $\Delta E\left(\mathrm{~S}_{1}, \mathrm{~S}_{2}\right)$ is of the order of $4000 \mathrm{~cm}^{-1}$ [28]. With DMABE, in which the $\mathrm{CN}$ group has been replaced by a $\mathrm{COOC}_{2} \mathrm{H}_{5}$ group with a slightly larger electron affinity, as deduced from the reduction potential of benzoic acid methyl ester $(-2.26 \mathrm{~V}$ vs. SCE) and that of benzonitrile $(-2.36 \mathrm{~V}$ vs. SCE) in MeCN [29]. There is hence still substantial room for reducing $\Delta E\left(\mathrm{~S}_{1}, \mathrm{~S}_{2}\right)$ before the $\mathrm{S}_{1}\left(\mathrm{~L}_{\mathrm{b}}\right) / \mathrm{S}_{2}\left(\mathrm{~L}_{\mathrm{a}}\right)$ energy ordering as occurring in DMABN is reversed to $\mathrm{S}_{2}\left(\mathrm{~L}_{\mathrm{b}}\right) / \mathrm{S}_{1}\left(\mathrm{~L}_{\mathrm{a}}\right)$. It is not clear at present whether a D/A molecule with $\mathrm{L}_{\mathrm{a}}$ as the lowest excited singlet state will show dual fluorescence or only a single emission band. In the case of MMD, for which the $S_{1}$ state has been supposed to be of $L_{a}$ character [7], the presence of dual fluorescence remains uncertain [25]. When the $S_{1}$ (LE) state gets substantial $L_{a}$ character, such with 2,4,6-tricyano- $N, N$-dimethylaniline, only a single LE fluorescence is observed [22].

\section{Conclusions}

From the upconversion data presented in Ref. [1] for the picosecond decay time $\tau_{2}$ of DMABN in MeCN at three temperatures, 

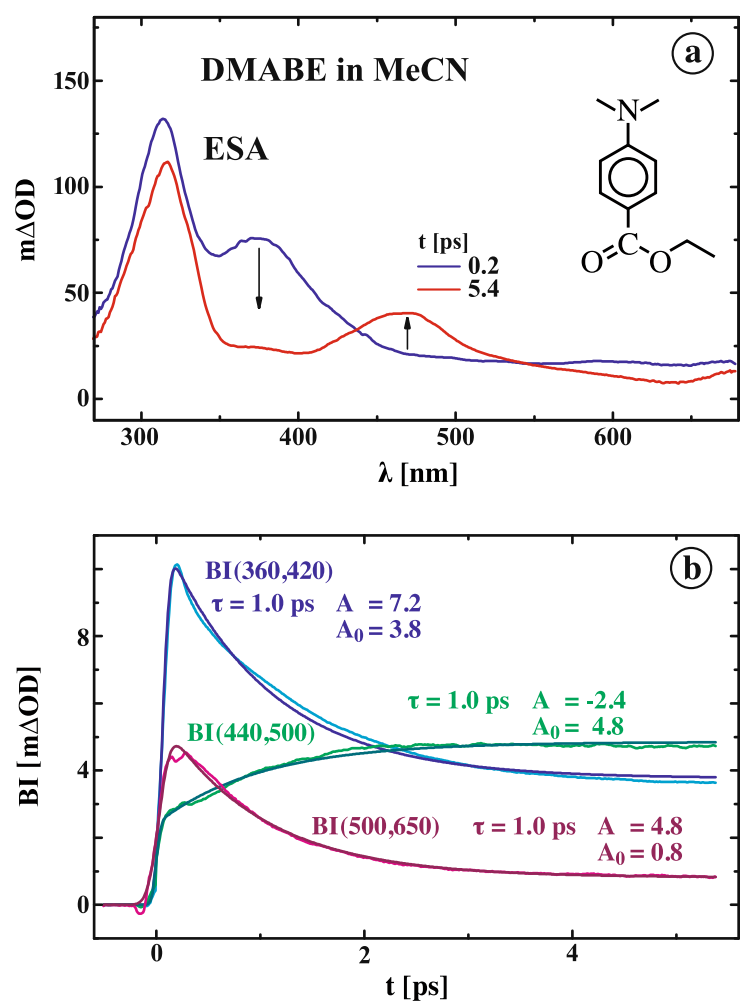

Fig. 4. (a) Excited state absorption (ESA) spectra at two pump-probe delay times of DMABE in acetonitrile $(\mathrm{MeCN})$ at $22{ }^{\circ} \mathrm{C}$. A correction for ground state bleaching and stimulated emission has been applied. The LE band with a maximum at $375 \mathrm{~nm}$ shows a decay, with a corresponding growing-in of the ICT band at around $465 \mathrm{~nm}$. (b) Single exponential decay curves of the band integrals $\operatorname{BI}(360,420), \operatorname{BI}(440,500)$ and $\operatorname{BI}(500,650)$ with $\mathrm{BI}=A \exp (-t / \tau)+A_{0}$, see text.

activation energies $E_{\mathrm{a}}$ and $E_{\mathrm{d}}$ with an exceptionally large uncertainty are obtained. From these data, conclusions on the entropy effects can obviously not be made. The same is the case for DMABE. The argument derived from computations that the ICT state of NTC6 has a nonplanar structure with a pyramidal C atom to which the amino nitrogen is attached, appears to be unlikely, as the ESA ICT spectrum resembles that of the benzonitrile radical anion with a fully conjugated phenyl ring. Because of the fact that both DMABN and P5C are planar in the $\mathrm{S}_{0}$ ground state, a discussion of the difference in the ICT reaction rate constant of these molecules in MeCN based on a presumed pretwist of DMABN is not relevant. The slower ICT reaction of P5C has previously been attributed to a larger nitrogen inversion barrier. Femtosecond ESA spectra of DMABE in MeCN show a decay of the LE state and a growing-in of the ICT state, both with a time of $1.0 \mathrm{ps}$. The assumption made in Ref. [1] that the lowest excited singlet state of DMABE is of $\mathrm{L}_{\mathrm{a}}$ character is questioned.

\section{Acknowledgement}

Many thanks are due to Prof. N.P. Ernsting (Humboldt University Berlin) for the use of the femtosecond absorption equipment in the investigations reported here.

\section{Appendix A. Supplementary material}

Supplementary data associated with this article can be found, in the online version, at doi:10.1016/j.cplett.2009.10.094.

\section{References}

[1] A. Pigliucci, E. Vauthey, W. Rettig, Chem. Phys. Lett. 469 (2009) 115.

[2] S.I. Druzhinin, N.P. Ernsting, S.A. Kovalenko, L. Pérez Lustres, T.A. Senyushkina, K.A. Zachariasse, J. Phys. Chem. A 110 (2006) 2955.

[3] K.J. Laidler, Theories of Chemical Reaction Rates, McGraw-Hill, New York 1969.

[4] K.A. Zachariasse, S.I. Druzhinin, W. Bosch, R. Machinek, J. Am. Chem. Soc. 126 (2004) 1705.

[5] S.I. Druzhinin, S.A. Kovalenko, T. Senyushkina, K.A. Zachariasse, J. Phys. Chem. A 111 (2007) 12878.

[6] C. Hättig, A. Hellweg, A. Köhn, J. Am. Chem. Soc. 128 (2006) 15672.

[7] I. Gómez, Y. Mercier, M. Reguero, J. Phys. Chem. A 110 (2006) 11455.

[8] A. Köhn, C. Hättig, J. Am. Chem. Soc. 126 (2004) 7399.

[9] I. Gómez, M. Reguero, M. Boggio-Pasqua, M.A. Robb, J. Am. Chem. Soc. 127 (2005) 7119.

[10] G.R. Stevenson, G.C. Wehrmann, R.C. Reiter, J. Phys. Chem. A 95 (1991) 901

[11] Z.R. Grabowski, K. Rotkiewicz, W. Rettig, Chem. Rev. 103 (2003) 3899.

[12] T. Okada, M. Uesugi, G. Köhler, K. Rechthaler, K. Rotkiewicz, W. Rettig, G. Grabner, Chem. Phys. 241 (1999) 327.

[13] C. Ma, W.M. Kwok, P. Matousek, A.W. Parker, D. Phillips, W.T. Toner, M. Towrie, J. Phys. Chem. A 106 (2002) 3294.

[14] S.U. Pedersen, T.B. Christensen, T. Thomasen, K. Daasbjerg, J. Electroanal. Chem. 454 (1998) 123.

[15] T. Shida, Electronic Absorption Spectra of Radical Ions, Elsevier, Amsterdam, 1988.

[16] W. Rettig, R. Gleiter, J. Phys. Chem. 89 (1985) 4676.

[17] A. Heine, R. Herbst-Irmer, D. Stalke, W. Kühnle, K.A. Zachariasse, Acta Cryst. B 50 (1994) 363.

[18] G.B. Jameson, B.M. Sheikh-Ali, R.G. Weiss, Acta Cryst. B 50 (1994) 703.

[19] I. Rückert, A. Hebecker, A.B.J. Parusel, K.A. Zachariasse, Z. Phys. Chem. 214 (2000) 1597

[20] A.B.J. Parusel, G. Köhler, S. Grimme, J. Phys. Chem. A 102 (1998) 6297.

[21] K.A. Zachariasse, Chem. Phys. Lett. 320 (2000) 8.

[22] K.A. Zachariasse et al., J. Phys. Chem. A 113 (2009) 2693.

[23] K.A. Zachariasse et al., J. Photochem. Photobiol. A: Chem. 105 (1997) 373.

[24] M. Grobys, K.A. Zachariasse, J. Inf. Record. 24 (1998) 405.

[25] K.A. Zachariasse et al., J. Photochem. Photobiol. A: Chem. 102 (1996) 59 (Erratum, ibidem 115 (1998) 259).

[26] R. Rotkiewicz, K.H. Grellmann, Z.R. Grabowski, Chem. Phys. Lett. 19 (1973) 315.

[27] S.A. Kovalenko, S.I. Druzhinin, T.A. Senyushkina, K.A. Zachariasse, in preparation.

[28] V.A. Galievsky, K.A. Zachariasse, Acta Phys. Pol. A 112 (2007) S-39.

[29] X. Allonas, Ecole Normale Supérieure de Chimie, Mulhouse, France, private communication. 